\title{
Central pancreatectomy revisited
}

\author{
Traian Dumitrașcu, Irinel Popescu
}

Center of General Surgery and Liver Transplantation, Fundeni Clinical Institute, Bucharest, Romania

\author{
Corresponding author: \\ Irinel Popescu, MD, PhD, FACS, FEBS \\ Center of General Surgery and Liver \\ Transplantation, Fundeni Clinical \\ Institute, Fundeni Street no. 258, \\ 022328, Bucharest, Romania \\ E-mail: irinel.popescu220@gmail.com \\ traian.dumitrascu@srchirurgie.ro
}

\section{ABSTRACT}

Central pancreatectomy (CP) is a parenchyma-sparing alternative resection to distal pancreatectomy, for benign and low malignant potential tumors located on the pancreatic isthmus and/ or body. Pancreatic metastases of other neoplasia might also benefit after a CP, in selected patients. Dagradi and Serio described the modern technique of $\mathrm{CP}$, while lacono introduced it in current clinical practice. An open CP represents the standard, but there is an emerging role for the minimally-invasive approach, which might become a standard for CP in experienced centers, particularly for the robotic approach. The rationale of a CP was to preserve the postoperative pancreatic functions because it implies the loss of a minimal amount of normal pancreatic tissue. However, the real clinical benefit of a CP is still controversial. High overall morbidity and pancreatic fistula rates were reported after a CP. However, most of the complications after a CP have been conservatively managed, with almost zero mortality. A CP has a minimal impact on the postoperative pancreatic functions; the diabetes mellitus rate after a CP is significantly lower, compared with the distal pancreatectomies. A proper selection of candidates for a CP is recommended. Thus, tumors located on the pancreatic isthmus are more likely to benefit after a $\mathrm{CP}$, because the alternative surgical technique in these patients is an extended left pancreatectomy, a procedure with increased risk of postoperative pancreatic insufficiencies. Individual patient-related factors should be taken into consideration in the selection of the patients. Thus, a CP should be used in young patients, non-obese and without diabetes mellitus, with a good biological status, which might be able to overcome the potential postoperative complications. A CP can be safely incorporated into an experienced pancreatic surgeon armamentarium, albeit it represents an uncommon pancreatic resection.

Abbreviations: Central pancreatectomy (CP); Physiologic and Operative Severity Score for the enumeration of Mortality and Morbidity (POSSUM).

Key words: Central pancreatectomy; Parenchyma-sparing pancreatic resection; Benign/ low malignant pancreatic tumors; Pancreatic metastasis; Morbidity; Pancreatic fistula; Diabetes mellitus

\section{INTRODUCTION}

Central pancreatectomy (CP) takes part from the group of parenchymasparing pancreatic resections, and it was introduced in clinical practice as alternative to standard pancreatic resections (i.e., pancreaticoduodenectomy 
and distal pancreatectomy), for a particular pathology. (1) The primary goal of a CP was to better preserve the postoperative pancreatic functions. (1) Currently, CP is considered a real alternative only to distal pancreatectomies. $(2,3)$

Benign and low malignant potential pancreatic lesions located on the pancreatic isthmus and/ or body represents the main indications for a $\mathrm{CP}(2,3)$, whenever a reasonable part of the distal pancreas can be preserved (i.e., $\geq 5 \mathrm{~cm}$ ), in the absence of a distal pancreas atrophy. (4)

The functional benefits have been shown in some studies $(2,3)$, but the clinical value of a CP is still a matter of debate and controversies. (5) Thus, the proponents of a CP argue with the very good functional results $(2,6-10)$, while the opponents of the method highlights the high morbidity rates, widely considered as higher, compared with the standard pancreatic resections. (11-14) Even in high-volume centers for pancreatic resections, favorable for a $\mathrm{CP}$, the percentages for this surgical procedure were reported to be less than $5.5 \%$ of all pancreatic resections. $(8,9,15-19)$

Beside a "central pancreatectomy", with the same significance were used the following terms: "median/ medial/middle/ intermediate pancreatectomy", "mesopancreatectomy" or "segmental pancreatectomy". $(4,20,21)$

The aim of the present paper was to provide an upto-date review of the indications, technical issues, and early and late outcomes after CP, based on the relevant literature.

\section{A short history of central pancreatic resections - the Dagradi-Serio-Iacono operation}

Several authors have suggested that the first central pancreatic resections were communicated by Guillemin in 1957 and Letton in 1959. $(11,20,22)$ Actually, neither Guillemin (23), nor Letton (24) performed a true pancreatic resection, and only the reconstruction part is similar to that reported on the modern technique of CP. $(4,21)$ Thus, Guillemin performed only a complete transection of the pancreatic isthmus, in a patient with chronic pancreatitis, and both pancreatic remnants were sutured to an omega shape jejunal loop. (23) Interestingly, the transection of the pancreas in Guillemin's patient was an unexpected intraoperative complication, because the surgeon first intended to do a side-to-side wirsungo-jejunostomy. (23)

Letton's patient presented with a complete posttraumatic transection of the pancreas, and the proximal pancreatic stump was sutured, while the distal pancre- atic remnant was anastomosed to a jejunal Roux en $Y$ loop. (24)

It appears that the first true central pancreatic resection was performed in 1909 by Finney from the Johns Hopkins Hospital (United States). (25) Finney's patient presented with a centrally located pancreatic cystadenoma; a central pancreatic resection was performed, but the two pancreatic stumps were sutured together. (25) Interestingly, in 2012, Di Benedetto and co-workers suggested a duct-to-duct anastomosis of the remnant pancreatic stumps after CP. (20)

The paternity of the modern technique of $\mathrm{CP}$ belongs to the group of surgeons from the University of Verona (Italy). (1) Thus, in 1982 Dagradi and Serio performed the first $\mathrm{CP}$ for an insulinoma, and the technique was, furthermore, introduced in current clinical practice by lacono. $(1,4,26)$

Although the technique of a CP was described in 1910 (25), with the modern version in 1984 (1), this conservative pancreatic resection was rarely performed till recently. Thus, 10 years ago no more than 100 patients with a CP were reported worldwide. $(8,27)$ However, the number of patients with a CP has significantly increased in the last 10 years, and 963 patients were reported in 2010. (2)

It appears that the first laparoscopic CP was performed in 2003 by Baca, while the first robotic CP was performed in 2004 by Giulianotti. (21)

An excellent, comprehensive and well-documented overview of the history of central pancreatic resections was recently released by lacono and co-workers. (21)

In summary, although the procedure was described many years ago, CP still represents, nowadays, an uncommon pancreatic resection. Dagradi and Serio described the modern technique of $\mathrm{CP}$, while lacono introduced it in current clinical practice. Thus, the Dagradi-Serio-lacono operation for a CP is entirely justified.

\section{Indications and contraindications for a central pancreatectomy - beyond the benign and low malignant potential pathology}

A recent meta-analysis has shown that a $\mathrm{CP}$ was indicated mainly for a benign or low malignant potential pathology of the pancreatic isthmus and/ or body. (2) The same findings were reported in large single center experiences with CP (table 1). (6,7,9,10,16, 17,19,28-30)

A widely accepted indication for a $\mathrm{CP}$ is represented by a serous cystadenoma. (2) However, the feasibility of a parenchyma-sparing resection in a patient diagnosed with a serous cystadenoma should not change the 
Table 1 - Large series with central pancreatectomies ( $\geq 25$ patients)

\begin{tabular}{|c|c|c|c|c|c|c|c|c|c|c|c|c|}
\hline $\begin{array}{l}\text { Institution, year of } \\
\text { publication }\end{array}$ & 离 & 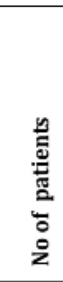 & 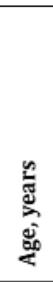 & Main indications & 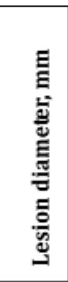 & 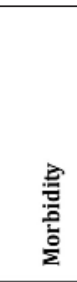 & 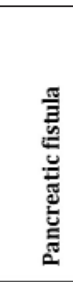 & 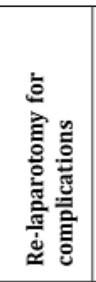 & 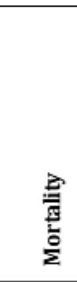 & 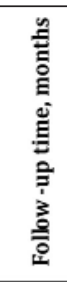 & 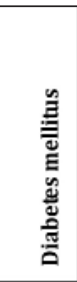 & 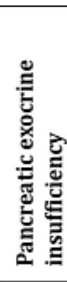 \\
\hline $\begin{array}{l}\text { San Raffaele Hospital, Milan, } \\
\text { Italy, } 2003(7)\end{array}$ & $1990-2000$ & 32 & 51 & $\begin{array}{l}\text { Neuroendocrine tumors, } \\
\text { serous/ mucinous cystadenoma }\end{array}$ & 34 & $62 \%$ & $50 \%$ & $3 \%$ & $0 \%$ & 66 & $10 \%$ & $6.2 \%$ \\
\hline $\begin{array}{l}\text { Heidelberg University, } \\
\text { Heidelberg, Germany, } 2006 \\
\text { (29) }\end{array}$ & $2001-2005$ & 40 & 53 & $\begin{array}{l}\text { Chronic pancreatitis, serous } \\
\text { cystadenoma }\end{array}$ & - & $42 \%$ & $10 \%$ & $5 \%$ & $2.5 \%$ & 29 & $3 \%$ & - \\
\hline $\begin{array}{l}\text { University of Verona, Verona, } \\
\text { Italy \& Massachusetts General } \\
\text { Hospital, Boston, USA, } 2007 \text { (9) }\end{array}$ & $1990-2005$ & 100 & 54 & $\begin{array}{l}\text { Neuroendocrine tumors, serous } \\
\text { cystadenoma }\end{array}$ & 26 & $58 \%$ & $44 \%$ & $0 \%$ & $0 \%$ & 54 & $4 \%$ & $5 \%$ \\
\hline $\begin{array}{l}\text { Indiana University, } \\
\text { Indianapolis, USA, } 2008 \text { (17) }\end{array}$ & $1998-2007$ & 34 & 49 & Chronic pancreatitis, IPMN & 25 & $47 \%$ & $29 \%$ & - & $0 \%$ & - & - & - \\
\hline $\begin{array}{l}\text { Edouard Herriot Hospital, } \\
\text { Lyon, France, } 2008(6)\end{array}$ & $1987-2005$ & 50 & 49 & $\begin{array}{l}\text { Neuroendocrine tumors, } \\
\text { serous/ mucinous cystadenoma }\end{array}$ & 24 & $46 \%$ & $8 \%$ & $12 \%$ & $0 \%$ & 55 & $0 \%$ & $20 \%$ \\
\hline $\begin{array}{l}\text { Hamburg University, Hamburg, } \\
\text { Germany, } 2010 \text { (16) }\end{array}$ & $1992-2007$ & 35 & 60 & $\begin{array}{l}\text { Neuroendocrine tumors, } \\
\text { serous/mucinous cystadenoma }\end{array}$ & - & $26 \%$ & $14 \%$ & $6 \%$ & $0 \%$ & 48 & $3 \%$ & $0 \%$ \\
\hline $\begin{array}{l}\text { Columbia University, New } \\
\text { York, USA, } 2010(10)\end{array}$ & $1997-2009$ & 73 & 58 & Serous cystadenoma, IPMN & 19 & $41 \%$ & $20 \%$ & $2.7 \%$ & $0 \%$ & 35 & $14 \%$ & - \\
\hline $\begin{array}{l}\text { Nagoya University, Nagoya, } \\
\text { Japan, } 2010(19)\end{array}$ & $1991-2006$ & 26 & 58 & $\begin{array}{l}\text { IPMN , serous/mucinous } \\
\text { cystadenoma }\end{array}$ & - & $38 \%$ & $31 \%$ & $11 \%$ & $0 \%$ & 71 & $0 \%$ & $4.2 \%$ \\
\hline $\begin{array}{l}\text { West China Hospital, Chengdu, } \\
\text { China, } 2012(30)\end{array}$ & $2000-2010$ & 44 & 49 & $\begin{array}{l}\text { Neuroendocrine tumors, } \\
\text { serous / mucinous cystadenoma }\end{array}$ & 34 & $75 \%$ & $55 \%$ & - & $0 \%$ & - & - & - \\
\hline $\begin{array}{l}\text { Beaujon Hospital, Clichy, } \\
\text { France, } 2014(28)\end{array}$ & $2000-2012$ & 100 & 55 & Neuroendocrine tumors, IPMN & 20 & $72 \%$ & $63 \%$ & $6 \%$ & $3 \%$ & 36 & $2 \%$ & $7 \%$ \\
\hline $\begin{array}{l}\text { Fundeni Clinical Institute, } \\
\text { Bucharest, Romania, 2015! }\end{array}$ & $2002-2014$ & 26 & 35 & $\begin{array}{l}\text { Serous cystadenoma, } \\
\text { neuroendocrine tumors }\end{array}$ & 30 & $58 \%$ & $38 \%$ & $27 \%$ & $0 \%$ & 74 & $0 \%$ & $0 \%$ \\
\hline
\end{tabular}

'IPMN - intraductal papillary mucinous neoplasms; 'Dumitrascu, unpublished data

surgical indications for this pathology, which usually has a surgical expectative approach. (31-33) A study at the Johns Hopkins University (United States) has shown that a large tumor diameter and pancreatic head location are independent risk factors for an aggressive biological behavior for a serous cystadenoma. (34) An algorithmic approach to an incidental cyst of the pancreas is associated with high rates of accurate diagnosis and management. (33)

A mucinous cystadenoma (figure $1, a$ and $b$ ) can be safely resected with a CP if the malignancy is not present or suspected. (2) The indication for resection in a mucinous cystadenoma of the pancreas is justified by the relatively high risk for malignant transformation, particularly in patients with a familial history of pancreatic cancer. $(35,36)$

Functional neuroendocrine pancreatic tumors such as insulinoma can be safely resected with parenchyma-sparing procedures such as $\mathrm{CP}$, when a simple enucleation is not possible. (28) A recent study has shown that almost $90 \%$ of the insulinomas have a benign biological behavior, and loco-regional lymph nodes dissection appears to have no benefit. (37) An analysis of 6,222 patients resected for insulinoma has shown that the enucleation was possible in $56 \%$ of the cases, while $35 \%$ of the patients underwent a distal/ subtotal pancreatectomy. (37) Selected patients from this latter group could potentially benefit from a CP.

For the non-functional neuroendocrine pancreatic tumors, several international guidelines recommend standard pancreatic resections, with loco-regional lymph nodes dissection, regardless the tumor size. (38) However, recent clinical data do not support the benefit of routine lymph nodes dissection in patients diagnosed with non-functional neuroendocrine pancreatic tumors. $(39,40)$ Furthermore, few studies have shown that surgical expectative and imaging monitoring is safe in selected patients. (41) It appears that cystic pancreatic neuroendocrine tumors have a less aggressive biological behavior, compared with solid only tumors.(42) Nevertheless, several papers have shown the feasibility and oncological safety of parenchyma-sparing pancreatic resections (including $\mathrm{CP})$ for non-functional pancreatic neuroendocrine tumors of the isthmus and/ or pancreatic body. (10, 28,39)

CP represents an alternative to distal pancreatectomy for selected patients with solid pseudopapillary tumors of the pancreas. (43) The widely reported benign behavior of these tumors, along with very low rates of loco-regional lymph nodes metastases justify a parenchyma-sparing approach for the solid pseudopapillary tumors of the pancreas, as recent studies have highlighted. (44-48) 


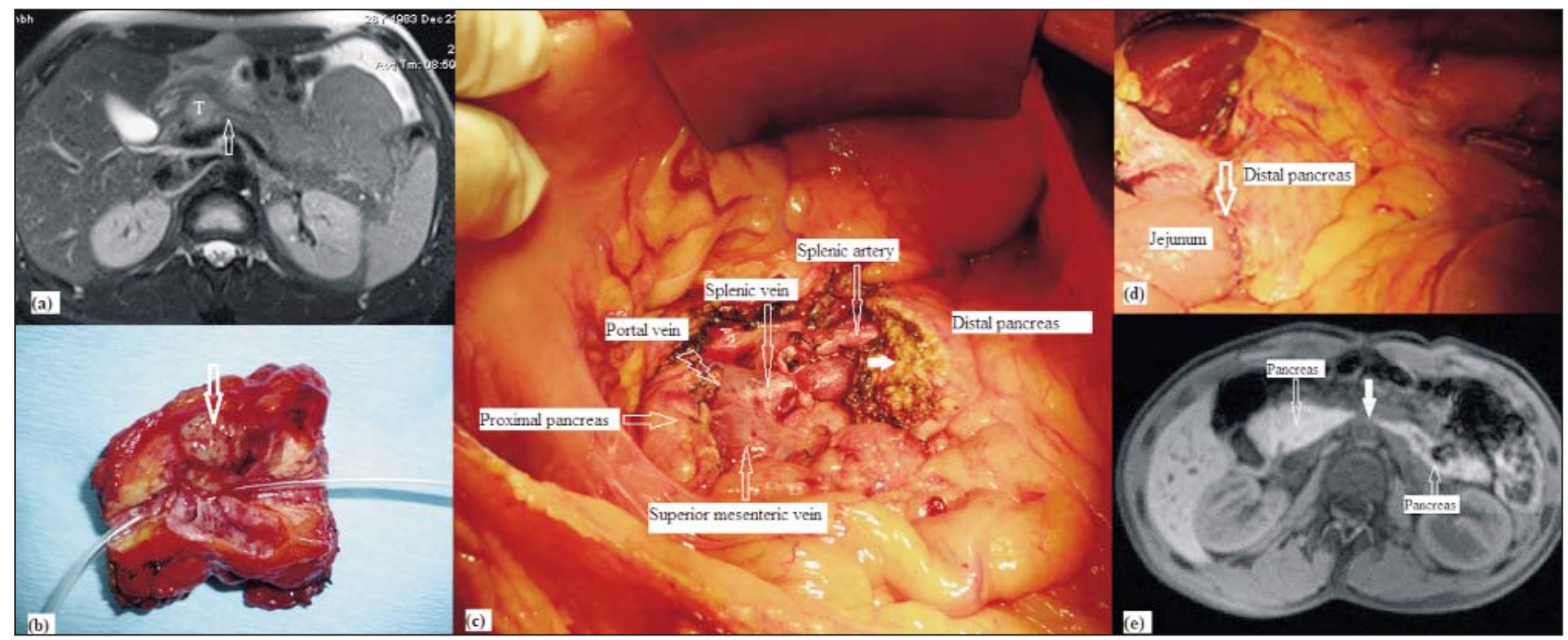

Figure 1 - (a) Magnetic resonance appearance of a mucinous cystadenoma of the pancreatic isthmus - it is observed a close relationship of the tumor to the Wirsung duct ( $\mathrm{T}$ - tumor; a white open arrow marks the Wirsung duct); (b) Central pancreatectomy for a mucinous cystadenoma - operative specimen (a white open arrow marks the tumor with the mucinous content); (c) Intraoperative aspect of a central pancreatectomy after removal of the operative specimen (a white filled arrow marks the Wirsung duct, with a small diameter); (d) Final intraoperative aspect after a central pancreatectomy (a white open arrow marks the end-to-end pancreaticojejunal anastomosis to the distal pancreatic remnant, with interrupted non-absorbable sutures); (e) Magnetic resonance appearance at 5 years after a central pancreatectomy for a pancreatic isthmus pancreatoblastoma (a filled open arrow marks the central pancreatic resection, without any recurrence) (Fundeni Clinical Institute experience, Bucharest, Romania)

Another indication for a CP is represented by the branch type intraductal papillary mucinous neoplasms. (2) The main type and the malignant branch type intraductal papillary mucinous neoplasms represent a contraindication for a parenchyma-sparing pancreatic resection, because high recurrence rates were reported. $(6,8,49,50)$ However, good oncological outcomes were reported in several studies, for the branch type intraductal papillary mucinous neoplasms with minimally-invasive or in situ adenocarcinoma, when a margins negative resection could be accomplished. $(17,51,52)$

Uncommon indications for a CP are chronic pancreatitis $(17,29)$ and pancreatic trauma. $(53)$

Large published series have shown that the main indications for a CP were represented by the neuroendocrine tumors (8\%-36\%), serous cystadenomas (20\%-44\%), mucinous cystadenomas (8\%-35\%), and branch type intraductal papillary mucinous neoplasms (12\%-35\%) (table 1). $(6,7,9,10,16,17,19,28-30)$ In a recent meta-analysis, the main indications for a $\mathrm{CP}$ were reported to be the serous/mucinous cystadenomas (28\%), followed by the neuroendocrine tumors (23\%) and intraductal papillary mucinous neoplasms (18\%). (2)

Beyond the benign and low malignant potential pathology, CP has been reported in several special malignancies of the pancreas. $(54,55)$ However, the safety of a parenchyma-sparing resection for a malignant pancreatic pathology is controversial.

A ductal adenocarcinoma of the pancreas represents an absolute contraindication for a $\mathrm{CP}$, because this surgical procedure cannot provide adequate locoregional lymph nodes dissection. $(4,19,28,56)$ In patients with intraoperative suspected malignant pathology, a frozen section pathology examination should be performed and, if the malignancy is confirmed, a conversion to a standard distal pancreatectomy with splenectomy and lymph nodes dissection is mandatory. $(1,49)$

For several special malignancies such as isolated pancreatic metastases of other neoplasia and pancreatoblastoma, a CP was demonstrated to be safe and effective, in selected patients (figure $1, e) .(54,55,57,58)$

Most of the patients reported in the literature, resected for pancreatic metastases of other neoplasia, underwent standard pancreatic resections $(59,60)$; however, the routine loco-regional lymph nodes dissection was not demonstrated to be of any value. (60) A standard pancreatic resection is recommended for this pathology in several centers (61), but other studies have shown the oncological safety of a parenchyma-sparing resection, when negative resection margins can be obtained. (60) 
In a recent review, a CP was performed in only $1.5 \%$ of the patients resected for pancreatic metastases of other neoplasia. (59) The Memorial SloanKettering Cancer Centre (United States) experience with resected pancreatic metastases of other neoplasia has shown the use of a CP in only $3 \%$ of the patients. (62) Our recent studies did not identify any significant differences of survivals between patients with CP or standard pancreatic resections for pancreatic metastases of other neoplasia, but only 16 patients with a CP were described in the literature until 2014 (Dumitrascu, unpublished data).

lacono and co-workers have summarized the indications and contraindications of a CP. $(4,21)$ Thus, a $\mathrm{CP}$ is indicated for a benign/ low malignant potential pathology or pancreatic metastases of other neoplasia, when the tumor is deeply located in the pancreatic isthmus and/ or body, and at least $5 \mathrm{~cm}$ of the distal remnant pancreas can be preserved. $(4,21)$ A ductal adenocarcinoma and distal pancreatic remnant atrophy represent contraindications for a CP. $(4,21)$

In summary, benign and low malignant pancreatic pathology represents the largest part of indications for a CP. This pathology includes mainly serous/ mucinous cystadenoma, the branch type intraductal papillary mucinous neoplasms, solid pseudopapillary tumors, and neuroendocrine tumors. Beyond the benign pathology, selected patients with pancreatic metastases of other neoplasia might also benefit after a CP.

\section{Technical issues in central pancreatectomy - no standard limits for resection, the fate of the distal pancreatic remnant, and the emerging role of a minimally-invasive approach}

A CP is classified as non-standardized pancreatic resection (63) because there are no standard limits for resection. Thus, in a CP the amount of remnant pancreas is more important than the removed one. The limits of resection in a CP are tailored to the tumor location and pathology.

The technique of a CP has been extensively described in several papers. $(4,64-69)$ Briefly, the middle part of the pancreas (i.e., isthmus and/ or pancreatic body) is resected, the proximal (i.e., cephalic) stump is closed (figure $1, c$ ), while a digestive anastomosis is performed with the distal pancreatic stump. (4)

An open approach has been used in most of the patients reported in the literature, with a CP. (2) A minimally-invasive $\mathrm{CP}$ was performed in only $3 \%$ of the patients: laparoscopic approach $-1.8 \%$, and robotic approach $-1.2 \%$.(2) The feasibility and safety of a minimally-invasive CP were previously shown. $(70,71)$
In Fundeni Clinical Institute (Bucharest, Romania), the first robotic central pancreatectomy was performed in 2014, with a pancreaticogastrostomy because the pancreatic parenchyma was soft; the postoperative outcome was uneventful (Popescu, unpublished data).

Although the worldwide reported number of patients with a minimally-invasive CP is still low (only 60 cases reported until 2014), it appears that the standardization of the technique will make a significant change in the future. $(70,71)$ Thus, in few experienced surgical centers, a minimally-invasive approach has become a standard for CP. (72) A laparoscopic approach has the potential to mitigate the invasiveness of a $\mathrm{CP}$ and, thus, to maximize the benefits. (73) Furthermore, a robotic approach has the potential to overcome the limitations of the conventional laparoscopy, particularly during the complex reconstructive part of a CP. (74)

Regardless the type of CP (open or minimallyinvasive), the distal pancreatic remnant approach represents the most important issue, because it is the primary source of surgical morbidity. The proximal pancreatic stump is usually sutured, either manually or stapled (up to $94 \%$ of the patients) (2), while for the distal pancreatic remnant there are more options.

In an excellent review performed by lacono and coworkers, there were described in details the technical options to treat the distal pancreatic stump. (4)

A recent review has shown that the distal pancreatic stump was sutured to the jejunum in approximately $58 \%$ of the patients with a CP (figure 1, $d$ ), while $38 \%$ underwent a pancreaticogastrostomy. (2) A pancreaticogastrostomy appears to be the first choice when a minimally-invasive CP is performed. $(70-72,75,76)$

Currently, there is no consensus regarding the best approach to the distal pancreatic remnant after a CP or a pancreaticoduodenectomy. Thus, Venara and coworkers have shown, in a single center experience, that the postoperative pancreatic fistula rate was higher when a pancreaticogastrostomy was performed. (77) The same trend was also shown in a recent metaanalysis. (2) Conversely, Xiang and co-workers have shown reduced pancreatic fistula rates after $\mathrm{CP}$, when a pancreaticogeastrostomy was used. (30) It is worth to mention also that recent meta-analyses of the randomized published studies associated the pancreaticogastrostomy with less overall (78-80) and severe (79) pancreatic fistula rates after pancreaticoduodenectomy, compared with the pancreaticojejunostomy, particularly in high-risk patients.(78) A previous randomized study has shown significantly less surgical complications after a pancreaticogastrostomy, compared with a pancreaticojejunostomy, in the subgroup of patients 
with a soft pancreatic parenchyma. (81)

The use of a stent for the Wirsung duct during pancreaticogastro/jejunostomy is controversial. A recent meta-analysis of the randomized published studies did not show reduced pancreatic fistula rates after pancreaticoduodenectomies, in patients with internal stents. (82) However, the use of an external stent was associated with reduced overall and clinically significant pancreatic fistula rates after pancreaticoduodenectomies. (83)

An interesting approach after a CP was recently suggested by Di Benedetto and co-workers - duct-toduct anastomosis of the Wirsung for both pancreatic remnants. (20) An internal lost stent into the duodenum was also used to protect the anastomosis. (20) The primary goal of this approach is to mitigate the consequences of a potential postoperative pancreatic fistula after a CP. (20) Thus, without any intestinal contamination, it is presumed to decrease the clinical impact of a pancreatic fistula. A similar type of reconstruction after CP was previously reported by Oida and co-workers. (84) It is worth to mention that a relatively similar approach was proposed in the first reported central pancreatic resection, more than 100 years ago. (25) However, at that time, no duct-to-duct anastomosis was performed, and the two pancreatic remnants were sutured together. (25) The feasibility of a duct-to-duct anastomosis after a CP was also shown in an experimental model. (85)

In summary, nowadays, the open CP represents the standard, but there is an emerging role for the minimally-invasive approach, which might become a standard for CP in experienced centers, particularly for the robotic approach. Currently, there is no consensus regarding the best approach to the distal pancreatic remnant; the use of either pancreaticojejonostomy or pancreaticogastrostomy is widely influenced by the surgeon expertise. However, a pancreaticogastrostomy appears to be safer, particularly when a minimallyinvasive CP is preferred, or a soft pancreatic parenchyma is present. Nevertheless, an end-to-end Wirsung duct anastomosis represents a novel and interesting option in selected cases; this approach might potentially mitigate the consequences of a postoperative pancreatic fistula after CP.

\section{Early results from central pancreatectomy - high morbidity rates, almost zero mortality}

Nowadays, the morbidity after pancreatic resections remains high, despite the centralization of this surgery in experienced centers. (86)

The high morbidity rates were the main arguments against the use of a CP. $(12,13)$ A recent study has identified a CP as independent risk factor for early postoperative in-hospital readmission. (14) However, a national study from the United States, including 102,417 patients with pancreatic resections, has associated the distal pancreatectomies and CP with significantly less severe morbidity and mortality rates, compared with the pancreaticoduodenectomies. (86)

The overall morbidity rates after $\mathrm{CP}$, reported in large series in the literature, ranged from $26 \%$ to $75 \%$, with a postoperative pancreatic fistula as the main complication (8\% to $63 \%$ of the patients) (table 1). (6,7, $9,10,16,17,19,28-30)$ A recent meta-analysis has shown an overall morbidity rate of $46 \%$, with a pancreatic fistula rate of $30 \%$ after CP. (2)

A recent review has shown that despite high rates of pancreatic fistula after a $\mathrm{CP}$, most of the patients can be conservatively managed. (87) It is worth to mention that the vast variety of the morbidity and pancreatic fistula rates were strongly influenced by the definition of complications and pancreatic fistula. The use of the standardized definitions for postoperative overall (88) and specific postpancreatectomy complications (89-91) was strongly recommended for a better surgical audit.

A high postoperative pancreatic fistula rate after a CP could be explained by the two potential sources proximal and distal pancreatic remnants (92); another explanation is the presence of a soft pancreas and a small Wirsung duct in the largest part of the patients. $(6,7,9,10,16,17,19,28-30)$ A soft pancreatic parenchyma and a small diameter of the Wirsung duct are significant risk factors for a postoperative pancreatic fistula after all types of pancreatic resections. (93)

A feared complication after $\mathrm{CP}$ is severe acute postoperative pancreatitis, because it has a life-threatening potential, and sometimes require completion of the distal pancreatic remnant. In Fundeni Clinical Institute (Bucharest, Romania) experience with $\mathrm{CP}$, the rate of severe acute postoperative pancreatitis was $7.8 \%$ (Dumitrascu, unpublished data). The onset of an acute severe pancreatitis after a CP might be related to some anatomical variants of vascularization to the distal pancreas. Thus, the exclusive arterial supply of the distal pancreas along the transverse/ inferior pancreatic artery, a situation that can be encountered in up to $25 \%$ of the patients, might lead to ischemia and pancreatic necrosis. (1) The re-exploration rate for complications after $\mathrm{CP}$ varies between $0 \%$ and $27 \%$ in the largest worldwide published series with CP (table 1). (6,7,9, 10,16,17,19,28-30)

A strong argument in favor of a $\mathrm{CP}$ is represented by the reduced mortality rates. Thus, a $0.8 \%$ mortality rate 
after CP was reported in a recent meta-analysis.(2) Furthermore, except for two high-volume centers with reported mortality rates of $2.5-3 \%(28,29)$, in all other worldwide reported large series, the mortality after CP was zero (table 1). $(6,7,9,10,16,17,19,30)$ It is worth to mention also that the deaths after a CP were mainly related to non-surgical causes, except for only two patients. $(2,28,29)$ Nevertheless, the reported mortality rates after $\mathrm{CP}$ are by far much lower than those reported after standard pancreatic resections. Thus, a recent national study in the United States, including 21,000 standard pancreatic resections, has shown 30 days and 90 days mortality rates of $3.7 \%$ and, respectively, 7.4\%. (94)

The meta-analyses comparing distal pancreatectomies with $\mathrm{CP}$ have shown increased overall morbidity $(2,3)$ and pancreatic fistula rates (3) after CP. No differences between the two surgical procedures were observed for the postoperative hemorrhage, clinically relevant pancreatic fistula, re-laparotomy and mortality rates. $(2,3)$

Goudard and co-workers have shown in a large single center experience that a $\mathrm{CP}$ is associated with significant morbidity.(28) Furthermore, a careful selection of patients who might benefit after either a CP or distal pancreatectomy is suggested.(28) Thus, a preoperative identification of patients who are at high risk to develop postoperative complications might potentially select the patients who are more likely to benefit after a CP.

Two studies have investigated potential predictors for postoperative complications after CP).(95,96) Thus, individual patient-related factors (i.e., age $\geq 40$ years and a body mass index $\geq 30 \mathrm{~kg} / \mathrm{m}^{2}$ ) have been identified as independent risk factors for the development of postoperative complications after a CP. (95) Furthermore, the Physiologic and Operative Severity Score for the enumeration of Mortality and Morbidity (POSSUM) appears to be a useful tool to predict morbidity after a CP. (96) However, the results of the above-mentioned study (96) should be regarded with caution because they might be influenced by the relatively small sample size. Recent reviews and meta-analyses have shown that POSSUM overpredicts morbidity after pancreatic resections and, thus, it has a doubtful predictive value. $(97,98)$ Thus, at the present time there are no strong arguments to support the use of a score to predict the risk of complications after pancreatic resections, because it might jeopardize an accurate clinical decision-making. (99)

In summary, the morbidity rates after $\mathrm{CP}$ are high, and pancreatic fistula represents the main complication. Although the overall pancreatic fistula rates after a
$\mathrm{CP}$ appear to be higher, compared with the distal pancreatectomy, however, there are no significant differences in the clinically relevant pancreatic fistula rates. Identification of a subgroup of patients who are at high risk to develop complications after a CP might potentially lead to a better selection of patients who might benefit after a CP. A low mortality rate represents a strong argument in favor of a $\mathrm{CP}$, in suitable patients. Finally, a selective use of a CP is recommended, in young patients, with a good biological status, which might be able to overcome the potential complications that may occur after a CP.

\section{The impact of a central pancreatectomy on the pancreatic functions on the long-term outcome}

A CP was proposed as alternative to standard pancreatic resections with the primary goal to preserve the pancreatic parenchyma and, thus, to mitigate the impact on the postoperative exocrine and endocrine functions. $(1,92)$ A recent study has shown that the loss of a normal pancreatic tissue is significantly lower after a CP, compared with a spleen-preserving distal pancreatectomy, and, thus, there is a potential postoperatively to preserve the pancreatic functions. (100)

Preservation of the exocrine and endocrine functions is of utmost importance in patients with benign and low malignant potential pancreatic pathology because a long-term survival is expected in these patients. Thus, the quality of life in patients resected for benign pancreatic pathology should not be jeopardized on the long-term outcome. (101)

A de novo or worsening diabetes mellitus represents an important issue after pancreatic resections, and the incidence is correlated with preexisting diabetes, presence of chronic pancreatitis or pancreatic cancer, and the volume of resected pancreas. $(102,103)$ A study has shown a $50 \%$ decrease in insulin secretion after standard pancreatectomies, with a more significant clinical impact after distal pancreatectomies. (104) Pancreatogenic diabetes mellitus is characterized by increased peripheral sensitivity to insulin and, thus, hypoglycemic episodes are more frequently encountered when the insulin is administered, sometimes with a significant clinical neurological impact. (102)

The incidence of de novo diabetes mellitus after distal pancreatectomies in patients without underlying chronic pancreatitis is reported in $7.5 \%$ to $36 \%$ of the patients. $(103,104)$ In the largest reported series from the literature with $\mathrm{CP}$, the incidence of postoperative diabetes mellitus ranges from $0 \%$ to $14 \%$ (table 1$)$. (6, $7,9,10,16,17,19,28-30)$ Two meta-analyses have shown 
that a $\mathrm{CP}$ is associated with significant lower rates for de novo and worsening diabetes mellitus, compared with distal pancreatectomies (5.5\% vs. $23.6 \%)$. $(2,3)$ Furthermore, the differences between the postoperative new-onset diabetes mellitus rates are more significant when a CP is compared with an extended left pancreatectomy (11\% vs. $57 \%$ ).(105)

Historically, the postoperative pancreatic exocrine insufficiency rates after distal pancreatectomies were reported to be of up to $61 \%$; however, a recent study has shown almost zero pancreatic exocrine insufficiency rates after distal pancreatectomies. (106) In the largest reported series from the literature with $\mathrm{CP}$, the incidence of postoperative pancreatic exocrine insufficiency rates ranges from $0 \%$ to $20 \%$ (table 1$).(6,7,9,10,16,17$, 19,28-30) Two meta-analyses have shown that a CP is associated with significant lower rates for pancreatic exocrine insufficiency, compared with the distal pancreatectomies ( $11.9 \%$ vs. $19.1 \%)$. $(2,3)$

There are also studies that have shown that, on the long-term outcome, there are no significant differences between the patients with a CP and those with a distal pancreatectomy, with respect to the nutritional status (107) or the postoperative quality of life. (101)

In summary, a CP has a minimal impact on the postoperative pancreatic functions. A de novo or worsening diabetes mellitus rates after a CP are significantly lower, compared with the distal pancreatectomies.

\section{CONCLUSIONS}

A CP can be safely incorporated into an experienced pancreatic surgeon armamentarium, albeit it represents an uncommon pancreatic resection.

Although the benign and low malignant pancreatic pathology represents the largest part of indications, however, a CP can be safely used for several particular malignancies such as pancreatic metastases of other neoplasia.

Nowadays, the open approach represents the standard, but there is an emerging role for the minimally-invasive approach, which might become a standard for CP in experienced centers, particularly for the robotic approach.

The overall morbidity and pancreatic fistula rates after $\mathrm{CP}$ are high, but most of the postoperative complications can be conservatively managed. A pancreaticogastrostomy appears to be safer in patients with a soft pancreatic parenchyma. A low mortality rate represents a strong argument in favor of a CP.

Tumors located in the pancreatic isthmus are more likely to benefit after a $\mathrm{CP}$, because in these patients an alternative left extended pancreatectomy should be performed, with a high potential for an adverse impact on the pancreatic functions.

A selective use of a $\mathrm{CP}$ is recommended, in young patients, non-obese and without diabetes mellitus, with a good biological status, which might be able to overcome the potential complications that may postoperatively occur.

\section{REFERENCES}

1. Iacono $\mathrm{C}$, Bortolasi $\mathrm{L}$, Serio $\mathrm{G}$. Is there a place for central pancreatectomy in pancreatic surgery? J Gastrointest Surg. 1998 Nov-Dec;2(6):509-16; discussion 516-7.

2. Iacono C, Verlato G, Ruzzenente A, Campagnaro T, Bacchelli C, Valdegamberi $A$ et al. Systematic review of central pancreatectomy and meta-analysis of central versus distal pancreatectomy. Br J Surg. 2013 Jun;100(7):873-85.

3. Xu SB1, Zhu YP, Zhou W, Xie K, Mou YP. Patients get more long-term benefit from central pancreatectomy than distal resection: a meta-analysis. Eur J Surg Oncol. 2013 Jun;39(6):567-74.

4. lacono C, Bortolasi L, Facci E, Nifosì F, Pachera S, Ruzzenente A, et al. The Dagradi-Serio-lacono operation central pancreatectomy. J Gastrointest Surg. 2007 Mar;11(3):364-76.

5. Del Chiaro M: Are there really indications for central pancreatectomy? JAMA Surg. 2014 Apr;149(4):364.

6. Adham M, Giunippero A, Hervieu V, Courbière M, Partensky C. Central pancreatectomy: single-center experience of 50 cases. Arch Surg. 2008 Feb;143(2):175-80; discussion 180-1.

7. Balzano G, Zerbi A, Veronesi P, Cristallo M, Di Carlo V. Surgical treatment of benign and borderline neoplasms of the pancreatic body. Dig Surg. 2003;20(6):506-10. Epub 2003 Sep 22

8. Bassi C: Middle segment pancreatectomy: a useful tool in the management of pancreatic neoplasms. J Gastrointest Surg. 2007 Jun;11(6):726-9.

9. Crippa S, Bassi C, Warshaw AL, Falconi M, Partelli S, Thayer SP, et al. Middle pancreatectomy: indications, short- and long-term operative outcomes. Ann Surg. 2007 Jul;246(1):69-76.

10. DiNorcia J1, Ahmed L, Lee MK, Reavey PL, Yakaitis EA, Lee JA, et al. Better preservation of endocrine function after central versus distal pancreatectomy for mid-gland lesions. Surgery. 2010 Dec;148(6):124754; discussion 1254-6.

11. Christein JD, Smoot RL, Farnell MB. Central pancreatectomy: a technique for the resection of pancreatic neck lesions. Arch Surg. 2006 Mar; 141(3):293-9.

12. Reber HA: Middle pancreatectomy: why I rarely do it. J Gastrointest Surg. 2007 Jun;11(6):730-2.

13. Roggin KK, Rudloff U, Blumgart LH, Brennan MF. Central pancreatectomy revisited. J Gastrointest Surg. 2006 Jun;10(6):804-12.

14. Sadot E, Brennan MF, Lee SY, Allen PJ, Gönen M, Groeger JS, et al. Readmission after pancreatic resection: causes and causality pattern. Ann Surg Oncol. 2014 Dec;21(13):4342-50.

15. Boggi U, Amorese G, De Lio N, Perrone V, D'Imporzano S, Croce C, et al. Central pancreatectomy with infra-mesocolic pancreatojejunostomy. Langenbecks Arch Surg. 2012 Aug;397(6):1013-21.

16. Cataldegirmen G, Schneider CG, Bogoevski D, Koenig A, Kaifi JT, Bockhorn $M$, et al. Extended central pancreatic resection as an alternative for extended left or extended right resection for appropriate pancreatic neoplasms. Surgery. 2010 Mar;147(3):331-8.

17. Lavu H, Knuth JL, Baker MS, Shen C, Zyromski NJ, Schmidt M, et al.. Middle segment pancreatectomy can be safely incorporated into a pancreatic surgeon's clinical practice. HPB (Oxford). 2008;10(6):491-7.

18. Pratt W1, Maithel SK, Vanounou T, Callery MP, Vollmer CM Jr. et al.. Postoperative pancreatic fistulas are not equivalent after proximal, distal, and central pancreatectomy. J Gastrointest Surg. 2006 Nov;10(9):126478; discussion 1278-9.

19. Shikano T, Nakao A, Kodera Y, Yamada S, Fujii T, Sugimoto H, et al. Middle pancreatectomy: safety and long-term results. Surgery. 2010 Jan;147(1): 
21-9.

20. Di Benedetto F, D'Amico G, Ballarin R, Tarantino G, Cautero N, Pecchi A, et al. Meso-pancreatectomy: new surgical technique for Wirsung reconstruction. J Am Coll Surg. 2012 Feb;214(2):e1-4.

21. lacono C, Ruzzenente A1, Bortolasi L, Guglielmi A. Central pancreatectomy: the Dagradi Serio lacono operation. Evolution of a surgical technique from the pioneers to the robotic approach. World J Gastroenterol. 2014 Nov 14;20(42):15674-81.

22. Hirono S, Yamaue H. Middle pancreatectomy for pancreatic neoplasms. J Hepatobiliary Pancreat Sci. 2010 Nov;17(6):803-7.

23. Guillemin $\mathrm{P}$, Bessot $\mathrm{M}$ : Chronic calcifying pancreatitis in renal tuberculosis: pancreatojejunostomy using an original technic. Mem Acad Chir (Paris). 1957 Nov 13-20;83(27-28):869-71. [Article in French]

24. Letton AH, Wilson JP. Traumatic severance of pancreas treated by Roux-Y anastomosis. Surg Gynecol Obstet. 1959 0ct;109:473-8.

25. Finney JM: Resection of the pancreas: report of a case. Ann Surg. 1910 Jun:51(6):818-29.

26. lacono C, Bortolasi L, Serio G. Indications and technique of central pancreatectomy-early and late results. Langenbecks Arch Surg. 2005 Jun;390(3):266-71. Epub 2005 Apr 27.

27. Aranha GV, Shoup M. Nonstandard pancreatic resections for unusual lesions. Am J Surg. 2005 Feb;189(2):223-8.

28. Goudard Y, Gaujoux S, Dokmak S, Cros J, Couvelard A, Palazzo M, et al. Reappraisal of central pancreatectomy a 12-year single-center experience. JAMA Surg. 2014 Apr;149(4):356-63.

29. Müller MW, Friess H, Kleeff J, Hinz U, Wente MN, Paramythiotis D, et al. Middle segmental pancreatic resection: an option to treat benign pancreatic body lesions. Ann Surg. 2006 Dec;244(6):909-18; discussion 918-20.

30. Xiang GM, Tan CL, Zhang H, Ran X, Mai G, Liu XB. Central pancreatectomy for benign or borderline lesions of the pancreatic neck: a single centre experience and literature review. Hepatogastroenterology. 2012 Jun;59(116):1286-9.

31. Gaujoux S, Brennan MF, Gonen M, D'Angelica MI, DeMatteo R, Fong Y, et al. Cystic lesions of the pancreas: changes in the presentation and management of 1,424 patients at a single institution over a 15-year time period. J Am Coll Surg. 2011 Apr;212(4):590-600; discussion 600-3.

32. Morris-Stiff G, Falk GA, Chalikonda S, Walsh RM. Natural history of asymptomatic pancreatic cystic neoplasms. HPB (Oxford). 2013 Mar;15(3):17581.

33. Robinson SM, Scott J, Oppong KW, White SA. What to do for the incidental pancreatic cystic lesion? Surg Oncol. 2014 Sep;23(3):117-25.

34. Khashab MA, Shin EJ, Amateau S, Canto MI, Hruban RH, Fishman EK, et al.: Tumor size and location correlate with behavior of pancreatic serous cystic neoplasms. Am J Gastroenterol. 2011 Aug;106(8):1521-6.

35. Beger HG, Poch B, Vasilescu C. Benign cystic neoplasm and endocrine tumours of the pancreas-when and how to operate-an overview. Int J Surg. 2014;12(6):606-14.

36. Buscarini E, Pezzilli R, Cannizzaro R, De Angelis C, Gion M, Morana G, et al. Italian consensus guidelines for the diagnostic work-up and follow-up of cystic pancreatic neoplasms. Dig Liver Dis. 2014 Jun;46(6):479-93.

37. Mehrabi A, Fischer L, Hafezi M, Dirlewanger A, Grenacher L, Diener MK, et al. A systematic review of localization, surgical treatment options, and outcome of insulinoma. Pancreas. $2014 \mathrm{Jul} ; 43(5): 675-86$.

38. Kunz PL, Reidy-Lagunes D, Anthony LB, Bertino EM, Brendtro K, Chan JA, et al. Consensus guidelines for the management and treatment of neuroendocrine tumors. Pancreas. 2013 May;42(4):557-77.

39. Birnbaum DJ, Gaujoux S, Cherif R, Dokmak S, Fuks D, Couvelard A, et al. Sporadic nonfunctioning pancreatic neuroendocrine tumors: prognostic significance of incidental diagnosis. Surgery. 2014 Jan;155(1):13-21.

40. Kim MJ, Choi DW, Choi SH, Heo JS, Park HJ, Choi KK, et al. Surgical strategies for non-functioning pancreatic neuroendocrine tumours. $\mathrm{Br} \mathrm{J}$ Surg. 2012 Nov;99(11):1562-8.

41. Crippa S, Partelli S, Zamboni G, Scarpa A, Tamburrino D, Bassi C, et al. Incidental diagnosis as prognostic factor in different tumor stages of nonfunctioning pancreatic endocrine tumors. Surgery. 2014 Jan;155(1):14553.

42. Koh YX, Chok AY, Zheng HL, Tan CS, Goh BK. A systematic review and meta-analysis of the clinicopathologic characteristics of cystic versus solid pancreatic neuroendocrine neoplasms. Surgery. 2014 Jul;156(1):8396.e2.

43. Dumitrascu T, Dima S: Central pancreatectomy-an alternative for surgical approach of the benign and low-malignant tumors of the pancreatic body in young patients. Chirurgia (Bucur). 2011 Sep-0ct;106(5):683-4. [Article in Romanian]

44. Butte JM, Brennan MF, Gönen M, Tang LH, D’Angelica MI, Fong Y, et al. Solid pseudopapillary tumors of the pancreas. Clinical features, surgical outcomes, and long-term survival in 45 consecutive patients from a single center. J Gastrointest Surg. 2011 Feb;15(2):350-7.

45. Kang CM, Choi SH, Kim SC, Lee WJ, Choi DW, Kim SW Predicting recurrence of pancreatic solid pseudopapillary tumors after surgical resection: a multicenter analysis in Korea. Ann Surg. 2014 Aug;260(2):348-55.

46. Kim MJ, Choi DW, Choi SH, Heo JS, Sung JY. Surgical treatment of solid pseudopapillary neoplasms of the pancreas and risk factors for malignancy. Br J Surg. 2014 Sep;101(10):1266-71.

47. Law JK, Ahmed A, Singh VK, Akshintala VS, Olson MT, Raman SP, et al. A systematic review of solid-pseudopapillary neoplasms: are these rare lesions? Pancreas. 2014 Apr;43(3):331-7.

48. Manuballa V, Amin M, Cappell MS. Clinical presentation and comparison of surgical outcome for segmental resection vs. Whipple's procedure for solid pseudopapillary tumor: Report of six new cases \& literature review of 321 cases. Pancreatology. 2014 Jan-Feb;14(1):71-80.

49. Crippa S1, Boninsegna L, Partelli S, Falconi M. Parenchyma-sparing resections for pancreatic neoplasms. J Hepatobiliary Pancreat Sci. 2010 Nov; 17(6):782-7.

50. Yang AD, Melstrom LG, Bentrem DJ, Ujiki MB, Wayne JD, Strouch M, et al. Outcomes after pancreatectomy for intraductal papillary mucinous neoplasms of the pancreas: an institutional experience. Surgery. 2007 0ct; 142(4):529-34; discussion 534-7.

51. Hirono S, Tani M, Kawai M, Ina S, Nishioka R, Miyazawa M, et al.: A central pancreatectomy for benign or low-grade malignant neoplasms. J Gastrointest Surg. 2009 Sep;13(9):1659-65.

52. Shimada K, Sakamoto Y, Esaki M, Kosuge T, Hiraoka N. Role of medial pancreatectomy in the management of intraductal papillary mucinous neoplasms and islet cell tumors of the pancreatic neck and body. Dig Surg. 2008;25(1):46-51.

53. López Penza P, Rosso E, Marzano E, Oussoultzoglou E, Bachellier P. Emergent central pancreatectomy for a blunt abdominal trauma. Cir Esp. 2013 0ct;91 (8):545-6. [Article in Spanish]

54. Dumitrascu T, Dima S, Popescu C, Gheonea DI, Ciurea T, Saftoiu A, et al. An unusual indication for central pancreatectomy-late pancreatic metastasis of ocular malignant melanoma. Chirurgia (Bucur). 2008 Jul-Aug;103(4):47985.

55. Dumitrascu T, Stanciulea O, Herlea V, Tomulescu V, lonescu M. Central pancreatectomy for pancreatoblastoma in a 16-year-old girl. J Pediatr Surg. 2011 Aug;46(8):e17-21.

56. Tol JA, Gouma DJ, Bassi C, Dervenis C, Montorsi M, Adham M, et al. Definition of a standard lymphadenectomy in surgery for pancreatic ductal adenocarcinoma: a consensus statement by the International Study Group on Pancreatic Surgery (ISGPS). Surgery. 2014 Sep;156(3):591-600.

57. Deguchi Y, Shimada K, Nara S, Esaki M, Sakamoto Y, Kosuge T, et al. Pancreaticojejunostomy with invagination of the punched pancreatic remnant after medial pancreatectomy and enucleation for multiple metastases of renal cell carcinoma: report of a case. Surg Today. 2009;39(12): 1086-90

58. Glanemann M, Shi B, Liang F, Sun XG, Bahra M, Jacob D, et al. Surgical strategies for treatment of malignant pancreatic tumors: extended, standard or local surgery? World J Surg Oncol 2008; 6:123-32.

59. Adler H, Redmond CE, Heneghan HM, Swan N, Maguire D, Traynor O, et al. Pancreatectomy for metastatic disease: a systematic review. Eur J Surg Oncol. 2014 Apr;40(4):379-86.

60. Reddy $\mathrm{S}$, Wolfgang $\mathrm{CL}$. The role of surgery in the management of isolated metastases to the pancreas. Lancet Oncol. 2009 Mar;10(3):287-93.

61. Bassi C, Butturini G, Falconi M, Sargenti M, Mantovani W, Pederzoli P. High recurrence rate after atypical resection for pancreatic metastases from renal cell carcinoma. Br J Surg. 2003 May;90(5):555-9.

62. Untch BR, Allen PJ. Pancreatic metastasectomy: the Memorial SloanKettering experience and a review of the literature. J Surg Oncol. 2014 Jan;109(1):28-30.

63. Aranha GV. Central (middle segment) pancreatectomy: a suitable operation for small lesions of the neck of the pancreas. Hepatogastroenterology. 2002 Nov-Dec;49(48):1713-5.

64. Efron DT, Lillemoe KD, Cameron JL, Yeo CJ. Central pancreatectomy with 
pancreaticogastrostomy for benign pancreatic pathology. J Gastrointest Surg. 2004 Jul-Aug;8(5):532-8.

65. Motoi F, Egawa S, Unno M. Middle pancreatectomy. J Hepatobiliary Pancreat Sci. 2012 Mar;19(2):148-51.

66. Müller MW, Assfalg V, Michalski CW, Büchler P, Kleeff J, Friess H. Middle segmental pancreatic resection: an organ-preserving option for benign lesions. Chirurg. 2009 Jan;80(1):14-21. [Article in German]

67. Partensky C, Apa D, Marchal F, Miziat A, Berger F. Medial pancreatectomy with pancreatogastric anastomosis in pancreatic neoplasms. Chirurgie. 1998 Sep;123(4):363-7. [Article in French]

68. Popescu I. Central pancreatectomy. In: Khatri VJ, editor. Atlas of Advanced Operative Surgery. Philadelphia: Elsevier 2013; p. 232-9.

69. Vibert E, Regimbeau JM, Sauvanet A. Technique of medial pancreatectomie. Ann Chir. 2003 May;128(4):268-72. [Article in French]

70. Kang $\mathrm{CM}$, Lee $\mathrm{JH}$, Lee WJ: Minimally invasive central pancreatectomy: current status and future directions. J Hepatobiliary Pancreat Sci. 2014 Dec;21(12):831-40.

71. Machado MA, Surjan RC, Epstein MG, Makdissi FF. Laparoscopic central pancrea-tectomy: a review of 51 cases. Surg Laparosc Endosc Percutan Tech. 2013 Dec;23(6):486-90.

72. Song KB, Kim SC, Park KM, Hwang DW, Lee JH, Lee DJ, et al.: Laparoscopic central pancreatectomy for benign or low-grade malignant lesions in the pancreatic neck and proximal body. Surg Endosc. 2015 Apr;29(4):937-46.

73. Rotellar F, Pardo F. Laparoscopic middle pancreatectomy minimizes the procedure and maximizes the benefit. Surgery. 2010 Jun;147(6):895.

74. Abood GJ, Can MF, Daouadi M, Huss HT, Steve JY, Ramalingam L, et al. Robotic-assisted minimally invasive central pancreatectomy: technique and outcomes. J Gastrointest Surg. 2013 May;17(5):1002-8.

75. Addeo P, Marzano E, Nobili C, Bachellier $P$, Jaeck D, Pessaux P. Robotic central pancreatectomy with stented pancreaticogastrostomy: operative details. Int J Med Robot. 2011 Sep;7(3):293-7.

76. Kim DH, Kang CM, Lee WJ, Chi HS. Robotic central pancreatectomy with pancreaticogastrostomy (transgastric approach) in a solid pseudopapillary tumor of the pancreas. Hepatogastroenterology. 2011 Sep-0ct;58(110111):1805-8.

77. Venara A, de Franco V, Mucci S, Frampas E, Lermite E, Regenet N, et al. Central pancreatectomy: comparison of results according to the type of anastomosis. J Visc Surg. 2012 Apr;149(2):e153-8.

78. Hallet J, Zih FS, Deobald RG, Scheer AS, Law CH, Coburn NG, et al. The impact of pancreaticojejunostomy versus pancreaticogastrostomy reconstruction on pancreatic fistula after pancreaticoduodenectomy: meta-analysis of randomized controlled trials. HPB (Oxford). $2015 \mathrm{Feb} ; 17(2): 113-22$.

79. Liu FB, Chen JM, Geng W, Xie SX, Zhao YJ, Yu LQ, et al. Pancreaticogastrostomy is associated with significantly less pancreatic fistula than pancreaticojejunostomy reconstruction after pancreaticoduodenectomy: a meta-analysis of seven randomized controlled trials. HPB (Oxford). 2015 Feb;17(2):123-30.

80. Xiong JJ, Tan CL, Szatmary P, Huang W, Ke NW, Hu WM, et al. Metaanalysis of pancreaticogastrostomy versus pancreaticojejunostomy after pancreaticoduodenectomy. Br J Surg. 2014 Sep;101(10):1196-208.

81. Bassi C, Falconi M, Molinari E, Salvia R, Butturini G, Sartori N, et al.: Reconstruction by pancreaticojejuno-stomy versus pancreaticogastrostomy following pancreatectomy: results of a comparative study. Ann Surg. 2005 Dec;242(6):767-71.

82. Xiong JJ, Altaf K, Mukherjee R, Huang W, Hu WM, Li A, et al.: Systematic review and meta-analysis of outcomes after intraoperative pancreatic duct stent placement during pancreaticoduodenectomy. Br J Surg. 2012 Aug; 99(8):1050-61.

83. Patel K, Teta A, Sukharamwala P, Thoens J, Szuchmacher M, DeVito P. External pancreatic duct stent reduces pancreatic fistula: a meta-analysis and systematic review. Int J Surg. 2014;12(8):827-32.

84. Oida Y, Imaizumi T, Dowaki S, Tobita K, Ohtani Y, Mukai M, et al.: End-toend anastomosis after medial pancreatectomy for tumor. Hepatogastroenterology. 2007 Jun;54(76):1266-8.

85. Ota A, Kusano M, Ishii H, Hoshino M, Nakamura A, Koike $\mathrm{Y}$, et al. A new reconstructive procedure after segmental pancreatectomy: an experimental study of pancreatic end-to-end (duct-to-duct) anastomosis. J Hepatobiliary Pancreat Surg. 2001;8(4):342-8.

86. Simons JP, Shah SA, Ng SC, Whalen GF, Tseng JF. National complication rates after pancreatectomy: beyond mere mortality. J Gastrointest Surg. 2009 0ct; 13(10):1798-805.

87. Zhou YM, Zhang XF, Wu LP, Su X, Li B, Shi LH. Pancreatic fistula after central pancreatectomy: case series and review of the literature. Hepatobiliary Pancreat Dis Int. 2014 Apr;13(2):203-8.

88. Dindo D, Demartines N, Clavien PA. Classification of surgical complications: a new proposal with evaluation in a cohort of 6336 patients and results of a survey. Ann Surg. 2004 Aug;240(2):205-13.

89. Bassi C, Dervenis C, Butturini G, Fingerhut A, Yeo C, Izbicki J, et al. Postoperative pancreatic fistula: an international study group (ISGPF) definition. Surgery. 2005 Jul;138(1):8-13.

90. Wente MN, Bassi C, Dervenis C, Fingerhut A, Gouma DJ, Izbicki JR, et al.: Delayed gastric emptying (DGE) after pancreatic surgery: a suggested definition by the International Study Group of Pancreatic Surgery (ISGPS). Surgery. 2007 Nov;142(5):761-8.

91. Wente MN, Veit JA, Bassi C, Dervenis C, Fingerhut A, Gouma DJ, et al. Postpancreatectomy hemorrhage (PPH): an International Study Group of Pancreatic Surgery (ISGPS) definition. Surgery. 2007 Jul;142(1):20-5.

92. Ionescu M, Dumitrascu T, Stroescu C, Ciurea S, Pietrareanu D, Mitulescu $\mathrm{G}$, et al. Central pancreatectomy - indications, technique, outcomes. Chirurgia (Bucur). 2005 Sep-0ct;100(5):429-35. [Article in Romanian]

93. McMillan MT, Vollmer CM. Predictive factors for pancreatic fistula following pancreatectomy. Langenbecks Arch Surg. 2014 0ct;399(7):811-24.

94. Swanson RS, Pezzi CM, Mallin K, Loomis AM, Winchester DP. The 90-day mortality after pancrea tectomy for cancer is double the 30-day mortality: more than 20,000 resections from the National Cancer Data Base. Ann Surg Oncol. 2014 Dec;21(13):4059-67.

95. Dumitrascu T, Barbu ST, Purnichescu-Purtan R, lonescu M, Popescu I. Risk factors for surgical complications after central pancreatectomy. Hepatogastroenterology. 2012 Mar-Apr;59(114):592-8.

96. Dumitrascu T, Barbu ST, Ionescu M, Popescu I. POSSUM, a potentially useful tool for prediction of morbidity in patients undergoing central pancreatectomy. Chirurgia (Bucur). 2012 Jul-Aug;107(4):447-53.

97. Chen T, Wang H, Wang H, Song Y, Li X, Wang J. POSSUM and P-POSSUM as predictors of postoperative morbidity and mortality in patients undergoing hepato-biliary-pancreatic surgery: a meta-analysis. Ann Surg Oncol. 2013 Aug;20(8):2501-10.

98. Wang H, Chen T, Wang H, Song Y, Li X, Wang J. A systematic review of the Physiological and Operative Severity Score for the enUmeration of Mortality and morbidity and its Portsmouth modification as predictors of post-operative morbidity and mortality in patients undergoing pancreatic surgery. Am J Surg. 2013 Apr;205(4):466-72.

99. Hackert T, Buchler MW. Invited commentary on "a systematic review of POSSUM and P-POSSUM as predictors of postoperative morbidity and mortality in patients undergoing pancreatic surgery". Am J Surg. 2013 Apr;205(4):473-4.

100. Dumitrascu T, Scarlat A, Ionescu M, Popescu I. Central pancreatectomy versus spleen-preserving distal pancreatectomy: a comparative analysis of early and late postoperative outcomes. Dig Surg. 2012;29(5):400-7.

101. van der Gaag NA, Berkhemer OA, Sprangers MA, Busch OR, Bruno MJ, de Castro SM, et al. Quality of life and functional outcome after resection of pancreatic cystic neoplasm. Pancreas. 2014 Jul;43(5):755-61.

102. Maeda H, Hanazaki K. Pancreatogenic diabetes after pancreatic resection. Pancreatology. 2011;11(2):268-76.

103. Shirakawa S, Matsumoto I, Toyama H, Shinzeki M, Ajiki T, Fukumoto T, et al. Pancreatic volumetric assessment as a predictor of new-onset diabetes following distal pancreatectomy. J Gastrointest Surg. 2012 Dec;16(12): 2212-9.

104. Menge BA, Schrader H, Breuer TG, Dabrowski Y, Uhl W, Schmidt WE, et al. Metabolic consequences of a $50 \%$ partial pancreatectomy in humans. Diabetologia. 2009 Feb;52(2):306-17.

105. Ocuin LM, Sarmiento JM, Staley CA, Galloway JR, Johnson CD, Wood WC, et al. Comparison of central and extended left pancreatectomy for lesions of the pancreatic neck. Ann Surg Oncol. 2008 Aug;15(8):2096-103.

106. Speicher JE, Traverso LW. Pancreatic exocrine function is preserved after distal pancreatectomy. J Gastrointest Surg. 2010 Jun;14(6):100611

107. Shibata S, Sato T, Andoh H, Yasui O, Yoshioka M, Kurokawa T, et al. Outcomes and indications of segmental pancreatectomy. Comparison with distal pancreatectomy. Dig Surg. 2004;21(1):48-53. Epub 2003 Dec 29. 